\title{
Framework for scenario development in LCA
}

\section{Journal Article}

\section{Author(s):}

Pesonen, Hanna -Leena; Ekvall, Tomas; Fleischer, Günter; Huppes, Gjalt; Jahn, Christina; Klos, Zbigniew S.; Rebitzer, Gerald; Sonnemann, Guido W.; Tintinelli, Alberto; Weidema, Bo P.; Wenzel, Henrik

\section{Publication date:}

2000

\section{Permanent link:}

https://doi.org/10.3929/ethz-b-000423069

\section{Rights / license:}

In Copyright - Non-Commercial Use Permitted

\section{Originally published in:}

International Journal of Life Cycle Assess 5(1), https://doi.org/10.1007/BF02978555 


\title{
SETAC-Europe LCA Working Group 'Scenario Development in LCA'
}

\section{Framework for Scenario Development in LCA}

\author{
Hanna-Leena Pesonen', Tomas Ekval1², Günter Fleischer ${ }^{3}$, Gjalt Huppes ${ }^{4}$, Christina Jahn ${ }^{5}$, Zbigniew S. Klos 6 , \\ Gerald Rebitzer $^{7}$, Guido W. Sonnemann ${ }^{8}$, Alberto Tintinelli' ${ }^{9}$ Bo P. Weidema ${ }^{10}$, Henrik Wenzel ${ }^{10}$ \\ ${ }^{1}$ University of Jyväskylä, School of Business and Economics, Environmental Management, PO Box 35 (MaE), 40351 Jyväskylä, \\ Finland; e-mail: hpesonen@tase.jyu.fi \\ ${ }^{2}$ Chalmers Industriteknik, Chalmers Teknikpark, 41288 Göteborg, Sweden; e-mail: tomas.ekvall@cit.chalmers.se \\ ${ }^{3}$ Technical University Berlin, Strasse des 17. Juni 135, 10623 Berlin, Germany; e-mail: LCA@itu301.ut.TU-Berlin.de \\ ${ }^{4}$ CML, PO Box 9518, 2300 RA Leiden, The Netherlands; e-mail: huppes@rulcml.leidenuniv.nl \\ ${ }^{5}$ ETH-Zentrum, Universitätstr. 31, 8092 Zürich, Switzerland; e-mail: jahn@tech.chem.ethz.ch \\ ${ }^{6}$ Poznan University of Technology, Institute of Machines and Vehicles, ul. Piotrowo 3, 60965 Poznan, Poland; \\ e-mail: zbigniew.klos@put.poznan.pl \\ ${ }^{7}$ Technical University Berlin, Strasse des 17. Juni 135, 10623 Berlin, Germany; e-mail: rebitzer@itu301.ut.TU-Berlin.de \\ ${ }^{8}$ Universitat Rovira i Virgili, Chemical Engineering Dep., Ctra. Salou s/n, 43006 Tarragona, Spain; e-mail: gsonnema@etseq.urv.es \\ ${ }^{9}$ ENI Ricerche, Via E. Ramarini 32, 00016 Monterotondo Scalo. Italy; e-mail: atintinelli@enitecnologie.eni.it \\ ${ }^{10}$ Technical University of Denmark, Life Cycle Center, Institute for Product Development, Building 424, 2800 Lyngby, Denmark; \\ e-mail: bow@ipt.dtu.dk (Bo Weidema) and hwc@ipt.dtu.dk (Henrik Wenzel)
}

Corresponding author: Dr. Hanna-Leena Pesonen ${ }^{1}$

\section{DOI: http://dx.doi.org/10.1065/lca199912.011}

Abstract. This article is based on the work of the SETAC-Europe LCA Working Group 'Scenario Development in LCA', which has started its work in April 1998. The goal of the Working Group is to focus on the use of scenarios in Life Cycle Assessment (LCA). This article presents the results of the first phase of the Working Group. The previous definitions of scenarios include three common basic elements: the definition of alternative future circumstances, the path from the present to the future, and the inclusion of uncertainty in the concept. We define a scenario in LCA as " $a$ description of a possible future situation relevant for specific $L C A$ applications, based on specific assumptions about the future, and (when relevant) also including the presentation of the development from the present to the future."

On the basis of the scenario definition we distinguish between two basic approaches for scenario development in LCA studies: What-if scenarios and Cornerstone scenarios. What-if scenarios are used to gain operational information and to compare two or more alternatives in a well-known situation with a short time horizon where the researcher is familiar with the decision problem and can set defined hypothesis on the basis of existing data. The Cornerstone scenario approach offers strategic information for long term planning, new ways of seeing the world, and also guidelines in the field of study. Results of a study using the Cornerstone scenario approach often serve as a basis for further, more specific research where the scenarios can be defined according to What-if scenarios.

The frames of the scenarios are defined in the first phase of LCA, the goal and scope definition. Scenario development does, however, influence all of the following phases of LCA. The frames of the scenarios form the basis for modelling product systems and environmental impacts associated with products and services, which are not exactly known due to lacking information on parts of the life cycle.

Keywords: Environmental decision making; future research; Life Cycle Assessment; modelling; scenarios; SETAC-Europe; uncertainties

\section{Introduction}

"The future is no longer stable; it has become a moving target" claims Pierre Wack, an economist, who has developed the system of scenario planning for Shell together with Edward Newland and has ever since participated in scenario development with management teams around the world and lectured about the theme at Harvard Business School (WACK, 1985a). Wack's statement summarises extremely well the uncertainty of the world where the companies today livc in and also serves as an explanation for increasing demand for scenario planning.

Stationarity of the trends was characteristic to the 1950 s and 1960 s but in the $1970 \mathrm{~s}$ it was broken to dynamic crises. Past experiences to which decision-makers used to commit themselves included: long term predictability of the future, long term stationarity of prices and costs, low risks of options, and foremost an economic growth which was exponential only with manageable fluctuations in it. A fundamental change, however, occurred in the 1970s. Instead of the expansive growth that had continued since World War II, a turbulent phase of non-growth, a completely new situation with competition under conditions of structural overcapacity and new competitors from the newly industrialised countries, was suddenly reality. One major change after another emerged in an unprecedented fashion. As a result, previous ways of decision-making, which had worked well in the past, started to lose ground. Many companies experienced unpleasant surprises in their strategic decision-making. Some companies, instead, managed well in doing business under these new conditions. The turbulence of our time has first and foremost affected conditions and expectations for business decisions and made previous business experience almost obsolete as a standard for successful decisionmaking. (see e.g. MALASKA, 1983 and 1984). 
Unpredictability and uncertainty have thus become factors, which have to be dealt with in each and every decision-making situation within today's business. The only certainty seems to be that future will hold surprises. Scenario development is a tool for systematic observation of the environment of a company, to be better prepared for alternative emerging future circumstances, and also to actively construct one's own future. Only when the future options are well known, it is possible to play an active role in the development of the future!

The best known scenario studies are probably the reports of the Club of Rome (MEADows et al., 1972), which have had a great contribution to the use of scenarios in future research. These reports served as an example for other organisations in their future planning.

To address the above-discussed issues in the context of LCA, SETAC-Europe launched the Working Group 'Scenario development in LCA' in April 1998. The Working Group has focused on two goals. One is to find solutions (rules, algorithms) for problems that are arising especially from conducting prospective LCAs. Prospective LCAs study product systems, which do not yet exist in that form today (future product systems), because they describe new products or decisions on e.g. long term recycling strategies. Such assessments have to deal with specific problems, which are significantly different from those of LCAs reflecting existing product systems. The second goal is to find a procedure, which may be applied to modelling the parts of a product system which are unknown or uncertain or for which different alternatives may be chosen. In this case the researcher either has to decide to use one specific model or to model different scenarios in order to identify significant differences. In either case the LCA practitioner has to provide reasoning for the valid selection of certain alternatives for e.g. manufacturing processes, materials, waste management options as well as the applied methodological approaches for allocation, system boundaries, etc.

The work of the Working Group has been divided into four areas: scenario framework, life cycle inventory (LCI) modelling, life cycle impact assessment (LCIA) modelling, case studies. This article concentrates on the first area of the Working Group, i.e. the framework of scenarios in LCA studies. The goal of this area has been to define the relevant concepts for scenario development in LCA studies and to describe how these concepts relate to each other.

\section{Scenario Development in Other Disciplines}

\subsection{Definition review}

The term scenario is widely used in a broad sense in various areas. Especially in the field of military, games, theatre, software, and LCA the term scenario is used referring to the setting of frame conditions or a description of the system to be modelled. Other terms often found in this context include framework, outline plan, background story, and guidelines. Herman Kahn introduced the term scenario into planning in connection with military and strategic studies conducted by the Rand Corporation in the 1950 s and he further popularised the concept in the 1960 s as the director of the Hudson Institute (The Futures Group, 1994). In LCA different choices of the model, of the input parameters or the surrounding conditions have often been referred to as a scenario.

Working Group members have presented several definitions of scenarios found in literature, which can be found in Box 1. These definitions include three basic elements of scenarios: the definition of alternative future circumstances, the path from the present to the future and the inclusion of uncertainty about the future.

\section{Box 1: Definitions of scenarios}

Definitions of Scenarios
- Bartusik and Cabala (1997): "One possible picture of future
conditions of the object and its environment; above mentioned
conditions are described by characteristics of the results of given
sequences of events (situations) and factors which disturb the
natural run (evolution) of these sequences."
- Gausemeier et al. (1995): "A description of a complex future
situation that occurrence can not be predicted for sure as well as
the presentation of the development that could lead from the
present to the future."
- Hansmann (1983): "A description of the development of the object
of the analysis in alternative framework conditions."
Meristö (1991): "A holistic script about the future, which defines the
working environment of a company based on different assumptions
and describes the paths from present to the future." and "Possible,
but not necessarily probable views of the future."
- Mesarovic and Pestel (1974): "The consequences of possible
decisions, measures and events are called a scenario." (e.g.
population scenario)
von Reibnitz (1991): "Scenarios are descriptions of a future
situation and the development respectively the description of the
way which leads from the present into the future."
- Scholz (1996): "In contrary to prognoses, scenarios do not try to
predict the future. Scenarios do more try to "throw light on"
thinkable future possibilities."
- Vartia (1994): "Scenarios are used to describe that part of the
organisations' environment for which projections are difficult or
even impossible. Scenarios give the possibility to prepare for
alternative and uncertain future options without knowing anything
about the probability of the possible outcomes. This makes the
scenarios different from forecasts. Effective scenarios are distinct,
logical and they are different enough from each other so that they
are able to describe the central changing factors of the future and
place questions on existing assumptions."

The term scenario has been used in two different ways:

1. to describe a snapshot in time or the conditions of important variables at some particular time in the future;

2. to describe a future history - that is, the evolution from present conditions to one of several futures (The Futures Group, 1994).

According to The Futures Group (1994), at least when scenarios are used in policy analysis, the nature of evolutionary paths is often important since policies can deflect those paths. It should also be noted that the presentation of the development from the present to the future is not equivalent to dynamic modelling, it should rather be described as reasoning for the probability of a certain scenario giving snapshots of time explaining the development. 


\subsection{Practice of scenario development process}

In the 1980 s, Malaska (1983 \& 1984) has conducted a study on the practice of scenarios in business planning in Europe. Linneman \& Klein (1982) have done a similar study for the USA. Both of these studies have chosen to use the term 'Multiple Scenario Approach' when referring to the scenario development process. According to Malaska's study, there is no one single way of developing scenarios in a company but, instead, many different methods are used. He claims that in accordance with the uncertainty and unpredictability of the future it is understandable that flexibility and creativity are needed in the scenario development as well. More than a logical structure or a new kind of planning procedure, he suggests that scenario development is an approach, a joint working procedure basically aiming to cultivate and utilise the advanced intuitive knowledge of decision-makers and combine it with objective information (MALASKA, 1983). Scenario development method should be selected according to the requirements of the studied case, its targets, and the available resources (MannermaA, 1999). Numerous methods have been developed to create scenarios, ranging from simplistic to complex, qualitative to quantitative and the development of scenarios can range from a lengthy and intricate process to an abbreviated workshop.

The Futures Group (1994) has proposed a process of three steps for scenario development:

1. Preparation. Scenario space is defined and key driving forces thought to be important to the future of the domain are listed.

2. Development. Key measures and events are defined. Key measures might include forces such as economic growth, legislative environment, technological changes, etc. Every scenario in the set will include projections of the same measure. Probable events, which can impact the key measures (e.g. change the chains of causality that lead from the present to the future or make certain policies more or less likely to work) can shape the scenarios in several ways and should also be defined.

3. Reporting and Utilisation. The best documentation for scenarios is in most cases a simple set of charts and narratives describing the future presented by each scenario. In reporting the contrast of implications of the alternative worlds should be emphasised.

Meristö (1991) has studied the methods of using scenarios in practice in strategic planning and has developed an approach called action scenario approach. The main features of the action scenario approach are as follows:

1. Those who are responsible for the strategic decisions are also responsible for the action scenario approach and the whole process to formulate and illustrate the scenarios. This ensures the commitment needed in decisionmaking and in action.

2. The action scenario approach describes not only the alternatives of the future but also includes the strategy formulation based on those alternatives. This creates the flexibility of the strategies.

3. The action scenario approach combines futures studies with strategic planning as an integrated part and it is dependent of the planning process used in the company. This guarantees that no double system of planning is used and that the scenario approach will broaden the view of traditional strategic planning.

The World Business Council for Sustainable Development (WBCSD, 1997) has built scenarios to illustrate a number of plausible routes forward that pose challenges for business. In the scenario building approach of the WBCSD the construction of scenarios for an organisation requires clarity about the overall focus or theme, which arises from an appreciation of the users' mental maps and the current strategic agenda. When the focus or theme has been clarified, the main areas of required research are identified, and information gathered. The next step is to identify and analyse driving forces that will shape the environment. Following the identification of the driving forces, a set of plausible storylines can be contemplated. These need to be structured, with relevant interconnections identified, and with the scenario logics defined. Then scenarios are usable as new frames of reference.

The breadth of the scenario should range from issues that have already given rise to legislation soon to come into force to those, which have not attracted external concern as yet, but which the organisation has reason to believe will attract attention in the future (HUNT \& JOHNSON, 1995).

A worst-case scenario is one of the concepts often related to scenario development. It is a possibility by some combination of events and/or human error the probability of which seems, however, remote (WELFORD, 1994). Welford refers to the Bhopal case as an example of a worst-case scenario that turned out to become reality.

\section{Scenarios in LCA Studies}

On the basis of the above presented definitions of scenarios, we suggest the following definition of scenario in LCA studies: "A scenario in LCA studies is a description of a possible future situation relevant for specific LCA applications, based on specific assumptions about the future, and (when relevant) also including the presentation of the development from the present to the future." According to this definition, scenarios cover the possible future situations and each scenario may in turn contain one or more product alternatives to be studied within the scope of LCA.

The frames of scenarios are defined in the first phase of LCA, the goal and scope definition. Even though scenario development is primarily part of goal and scope definition it does, however, have influence on all the following phases of LCA. The modelling of the scenarios is done in LCI and LCIA. The setting (or frame conditions) of scenarios defined in the goal and scope definition gives the framework for the modelling and the models, in turn, have to follow these.

According to the definition a scenario includes a short description of the scenario and the specific assumptions (in detail) underlying this scenario. The description serves as a short introduction to the scenario. The assumptions then specify the scenario in detail. These assumptions are also used as the basis for modelling each scenario; e.g. in a study 
about different paper products with the same function, the scenario descriptions for the end-of-life phase could be: $100 \%$ incincration; $70 \%$ closed-loop recycling and $30 \%$ incineration; or $40 \%$ closed-loop recycling, $40 \%$ open-loop recycling and $20 \%$ landfill with or without prior incineration. These scenarios could reflect the situations of different future developments (more or less incineration and recycling capacity, new regulations, etc.).

Braunschweig \& Jahn (1998) state that scenarios in LCA studies may evaluate different elements or parameters of the product system (the term 'product system' relates to the system in reality and not the model of the product system) and/ or the surrounding environment. According to Hunt \& Johnson (1995), changes in the surrounding environment can include changing circumstances, such as changes in technology, environmental damage becoming tangible, and improved understanding of environmental science. According to Wack (1985b), scenarios can effectively organise a variety of seemingly unrelated economic, technological, competitive, political, and social information and translate it into a framework for judgement. In LCA studies a distinction between three different types of scenario applications can be made: technology scenarios, environment scenarios and valuation scenarios.

\subsection{Future research methods}

The use of scenarios is one of a number of future research methods. It has to be noted here that futures research is not a science; it does not have controlled experiments. Futures research (or 'future studies' or 'prospective studies'; futurists have not reached consensus on the name or definition of their activity; see more about this in Glenn, 1994c, and some related definitions in Box 2) utilises information from all of the sci- ences. Studying the future is not simply about economic projections or sociological analysis or technological forecasting, but a multi-disciplinary examination of change in all major areas of life to find the interacting dynamics that are creating the next age. Neither does there exist any agreement on the proper way to organise futures methods (GLENN, 1994c).

Future research methods for LCAs can be divided into six groups (CASPERSEN \& WeIDEMA, unpubl.):

1. Extrapolating methods, which are based on the belief that the future represents a logical extension of the past. Trend analysis, time series, regression, econometrics, and simulation modelling are tools of extrapolating methods. (Futures Group, 1994a)

2. Exploratory methods, which concentrate on structuring possible futures, typically using qualitative descriptions. Morphological analysis, relevance trees, mind mapping, and future wheel are representatives of the tools of this category. (Futures Group, 1994b; GLENN, 1994a)

3. Modelling describes the furure by identifying the determining mechanisms of past events and how these influence the future. Examples of these tools are analogy analysis, technological sequence analysis, stakeholder analysis, and structural analysis. (VANSTON, 1995)

4. Scenario methods arise from the belief that the future is essentially unpredictable. Considering the uncertainties included in the future, modelling will not lead into one future but rather to many different futures, each of which may be described in the form of a scenario. Scenario methods combine aspects of other tools with the aim of creating several scenarios.

5. Participatory methods find expert and stakeholder opinions and insights about the future more useful than rational methods. Tools used in participatory method include Delphi technique, scanning, focus groups, charrette,

Box 2: Glossary

\begin{tabular}{|c|}
\hline $\begin{array}{l}\text { Glossary } \\
\text { Forecast } \\
\text { A forecast is a probabilistic statement, which does not mean that you believe that the forecasted event will occur. (Glenn, 1994c) } \\
\text { For forecasts a number of possible futures have to be taken into account. Future pictures in form of a forecast have each a probability (objective or } \\
\text { subjective) that is neither } 1 \text { nor } 0 \text {. (GAUSEMEIER et al., 1995) }\end{array}$ \\
\hline $\begin{array}{l}\text { Futures research } \\
\text { Use of methods to identify systematically the consequences of political options and to identify alternative futures with policy implications for decision- } \\
\text { makers. Futures research is decision-oriented, i.e. it seeks to identify current forces that should be understood in order to make more intelligent } \\
\text { decisions. (GLENN, 1994a and 1994b) }\end{array}$ \\
\hline $\begin{array}{l}\text { Futures studies } \\
\text { Exploration of what might happen and what we might want to become. Future studies is subject- or question-oriented, e.g. what are the critical } \\
\text { technologies that will have the greatest influence over the next } 25 \text { years? (GLENN, 1994a and 1994b) }\end{array}$ \\
\hline $\begin{array}{l}\text { Prediction } \\
\text { A prediction is a statement that you believe will be true. (GLENN, 1994a and 1994b) }\end{array}$ \\
\hline $\begin{array}{l}\text { Prognosis } \\
\text { A conventional prognosis captures quantitatively the actual situation and calculates the future situation with the help of a formula. (VON REIBNITZ, 1991) } \\
\text { A future picture that occurrence because of scientific experience can be predicted (or rejected) with such a high probability that possible alternative } \\
\text { future pictures are negligible. The prognosis therefore has a probability of either } 1 \text { or } 0 \text {. (GAUSEMEIEA et al., 1995) } \\
\text { Prognoses can only be reliable as far as the present circumstances are largely unchanged. Therefore the time horizon of a prognosis is limited to } \\
\text { maximum one year into the future. (SCHOLZ \& TIETJE, 1996) }\end{array}$ \\
\hline $\begin{array}{l}\text { Projection } \\
\text { An estimate of the future possibilities based on historical data (i.e. a surprise-free base-line forecast). (GLENN, 1994a and 1994b) } \\
\text { The most general form of a future picture. No probability can be assigned to a projection. (GAUSEMEIER et al., 1995) }\end{array}$ \\
\hline ospective studies \\
\hline
\end{tabular}


Syncon, and future search conferences. (GORDON, 1994; GlenN, 1994b; Gordon \& GlenN, 1994)

6. Normative methods investigate how we want the future to be and how to obtain this goal. Objectives, that may be very discontinuous from the present trends are defined and then the normative method moves backwards to the present to identify the necessary steps for reaching these objectives (COATES, 1994). One normative method is "backcasting". Robinson (1982) uses the concept 'backcasting' to describe a corresponding method to the normative one. According to Robinson: "The major distinguishing characteristic of backcasting analysis is a concern, not with what futures are likely to happen, but with how desirable futures can be attained. It is thus explicitly normative, involving working backwards from the particular desirable future end-point to the present in order to determine the physical feasibility of that future and what policy measures would be required to reach that point."

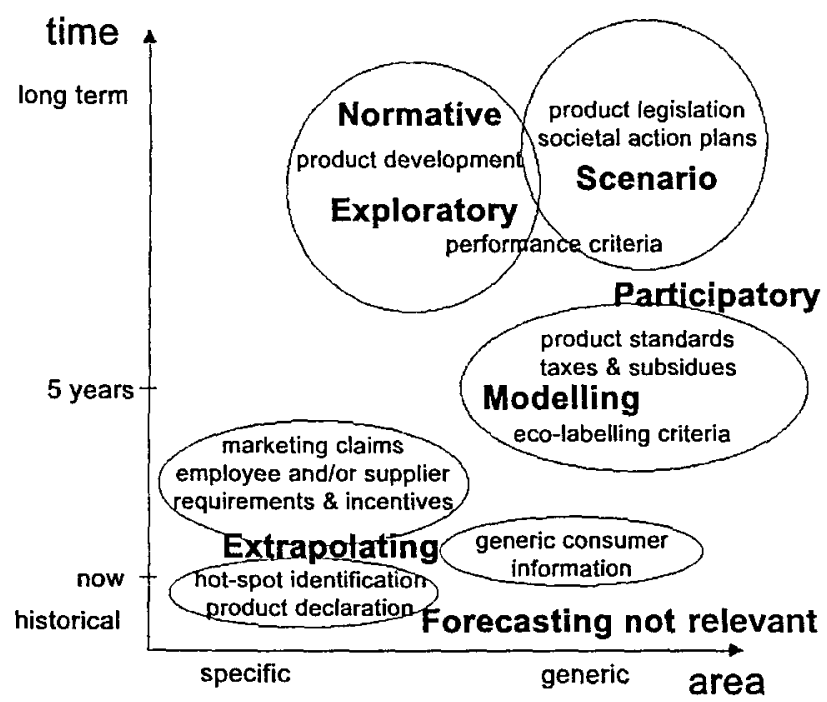

Fig. 1: Relevance of different future research methods in relation to applications of LCA (WEIDEMA, 1998b)

Fig. 1 presents the above-discussed six future research methods corresponding to the application areas of LCA according to Weidema (1998b). The scenario definition of the Working Group given above would not exclude the use of any of the methods presented in Fig. 1. In this case all of the future forecasting methods listed above would be possible tools for scenario development in LCA studies.

\subsection{Number of scenarios}

Every prospective LCA contains at least one (base) scenario (BRAUNSCHWEIG \& JAHN, 1998), which should be explicitly defined. In reality this is, however, not always the case, but instead, scenarios are quite often implicit assumptions behind the studied systems. Typically LCA studies include at least two scenarios: the base scenario 'everything continues as usual' and (an) alternative scenario(s) with some changes to the first one (see e.g. WeIDEMa, 1998a).
Wack (1985b) has given a suggestion about the appropriate number of scenarios in a study. He claims that there should never be more than four scenarios because otherwise the decision-making will become unmanageable for most decisionmakers. He suggests the ideal number of scenarios to be one plus two; that is, first the surprise-free base scenario (showing explicitly why and where it is fragile) and then two other different ways of seeing the world that focus on the critical uncertainties. Von Reibnitz (1991) proposes to concentrate on two scenarios only that are consistent and stable and are sufficiently different from each other. Also the suggestions of other authors (see e.g. MERISTO, 1991; HoKKANEN, 1997; The Futures Group, 1994) about the number of scenarios in a study agree with the principles presented by Wack and von Reibnitz. Defining a large number of alternative worlds is often neither necessary nor desirable. A smaller set of choices that encompasses the range of major challenges and opportunities is usually sufficient. (The Futures Group, 1994).

The suggestions above are applicable to Cornerstone scenarios, but in case of What-if scenarios a larger number of alternatives can also be studied (Cornerstone and What-if scenarios are defined in section 4).

\subsection{Time horizon of scenarios}

For what time period should a scenario be conducted? How far should a study look? There are no universal answers to these questions. The time span of scenarios has to be determined separately in each case and will be determined at least partly by business considerations such as the lifetime of existing plants and the lead time for developing new products or services.

Hunt \& Johnson (1995) suggest that environmental scenario development should, as far as possible, cover a time-scale commensurate with that used for business development strategy. According to Meristö (1991), the time horizon of a scenario is typically longer than that of usual strategic planning. In her study about scenario planning in European companies, the time horizon of the scenarios was for most companies between 6-15 years while their usual strategic planning includes a time span of only $3-5$ years.

Weidema (1993) has presented a typology of LCA application areas where he distinguishes between three categories based on time horizon: the operational, the tactical, and the strategic level. The operational level is characterised by being noncomparative and by the results being used directly on the product itself, the typical example being product declaration. The tactical level includes typically improvements being evaluated by comparison between products. The results are used to influence the surroundings of the product: producers, suppliers, employees, and customers. Typical examples would be ecolabelling criteria. The strategic level, instead, includes improvements evaluated in relation to an environmental target and the results are used to place the product in a larger context.

The time horizon of scenarios should be consistent with the goal of the study. In an LCA of a hydropower plant it might be relevant to look very far into the future, to the time when the hydropower plant is no longer used. In an LCA of a 
nuclear power plant, it might be relevant to consider the very long time spans that will pass before the nuclear waste becomes harmless. Factors causing dangers of trying to look too far ahead include rapid, unforeseeable changes in technology, increasing understanding of environmental sciences, which may change our common truths about environmental impacts, revolutionary changes in legislation or policy, or changes in the markets such as consumption patterns, supply of raw material, etc.

\section{Two Basic Approaches to Scenario Development in LCA Studies}

On the basis of the different definitions of scenarios discussed in section 2.1, two basic approaches of scenarios in the context of LCA studies are identified: What-if scenarios and Cornerstone scenarios (see also PESONEN, 1998).

\subsection{What-if scenarios}

The What-if scenario is the more widely used one of the two approaches in LCA studies. It is used to compare two or more options in a well-known situation where the researcher is familiar with the decision problem and can set defined hypothesis on the basis of existing data. These are often studies where some specific changes within the present system are tested and their implications to environmental impacts are studied. The results of a study using What-if scenarios are typically quantitative comparisons of the selected options: e.g. alternative $\mathrm{A}$ is better than alternative $\mathrm{B}$ by $\mathrm{x} \%$. This type of research could also be defined as one offering operational information in case of short or medium term decision-making situations. According to CHAINET (1998), operational information describes small changes of small scale systems with a short time horizon.

\subsection{Cornerstone scenarios}

The Cornerstone scenario approach, instead, does not necessarily give quantified results comparing any pre-set alternatives. It offers guidelines in the field of study and typically serves as a base for further research. In the Cornerstone approach the researcher chooses several options, which can be very different, in order to get an overall view of the stud- ied field - these alternatives then serve as 'cornerstones' of the studied field. The results of the Cornerstone scenario approach can point out a potential direction of future development or at least give some information about (an) alternative path/s of development in the studied area that is/ are certainly not possible. The Cornerstone scenario approach offers a tool for long term planning and the nature of this type of study and the information gained from it is more strategic than in the What-if scenario approach. Strategic information refers to large and possibly qualitative changes of large scale systems with long time horizons (CHAINET, 1998). Cornerstone scenarios can offer new ways of seeing the world, which allows the decision-makers to break out of one-eyed view (i.e. 'out of the box' thinking). Cornerstone scenarios can thus serve as means to reperceive reality.

Results of a study using Cornerstone scenario approach often serve as a basis for further, more specific research where the scenarios can be defined according to What-if scenarios. Wack (1985b) has also paid attention to the importance of starting with scenarios at a more general level (in his definitions first-generation scenarios) and then work further towards more specific ones (decision scenarios). He claims that one cannot start with a narrow focus because key issues (or dimensions) will thus be missed: "You must wide-angle first to capture the big picture and then zoom in on the details".

Several similarities between the features of the two basic research approaches, quantitative and qualitative research (see e.g. Burns \& BuSH, 1998) and the two defined basic methods of scenario development can be stated. Table 1 summarises the features of What-if scenarios and Cornerstone scenarios defined on the basis of differences between quantitative and qualitative research.

According to the ISO 14040 standard, possible internal application areas of LCA studies (ISO 14040, 1997) include: product development and improvement, strategic planning, public policy making, marketing, and other. We believe that for typical strategic planning and public policy planning research using Cornerstone approach is more appropriate. All the other applications mentioned here require more operational information and would thus include research methods applying What-if scenarios.

Table 1: Features of the basic scenario approaches (PESONEN, 1998)

\begin{tabular}{|c|c|}
\hline What-if scenarios & Cornerstone scenarios \\
\hline $\begin{array}{l}\text { - Field of research is well known; researcher is familiar with the } \\
\text { object of the research } \\
\text { - Research object is simple } \\
\text { - Well defined research plan, standardised research } \\
\text { - Purpose of the study is to investigate consequences of specific, } \\
\text { discrete assumptions and uncertainties, which do not have any } \\
\text { long-term implications } \\
\text { - Comparison of existing systems (process alternatives, product } \\
\text { modifications, etc.) } \\
\text { - Operational or tactical information }\end{array}$ & $\begin{array}{l}\text { - Field of research is new, unknown to the researcher } \\
\text { - Research object is complex } \\
\text { - Open research plan, scenarios are developed in the course of the } \\
\text { study } \\
\text { - Purpose of the research is to increase understanding about the } \\
\text { studied object } \\
\text { - Design and development (of new products, technologies, etc.) } \\
\text { - Strategic information } \\
\text { - Often serve as a base for further, more specific research with } \\
\text { What-if scenarios }\end{array}$ \\
\hline
\end{tabular}


Fig. 2 summarises the use of Cornerstone and What-if approaches corresponding to the two dimensions of application areas of LCA studies, time and complexity. If the research problem is specific and covers a short to medium time horizon, What-if approaches are typically used. If the time horizon grows and the problem area becomes more complex, Cornerstone approaches are more suitable. Whatif and Cornerstone approaches describe the two ends of the continuum from very strictly defined scenarios to complex research settings in the Cornerstone approach. Scenarios are, however, not limited just to these two ends of the continuum, but different variations including features of the two basic approaches are possible.

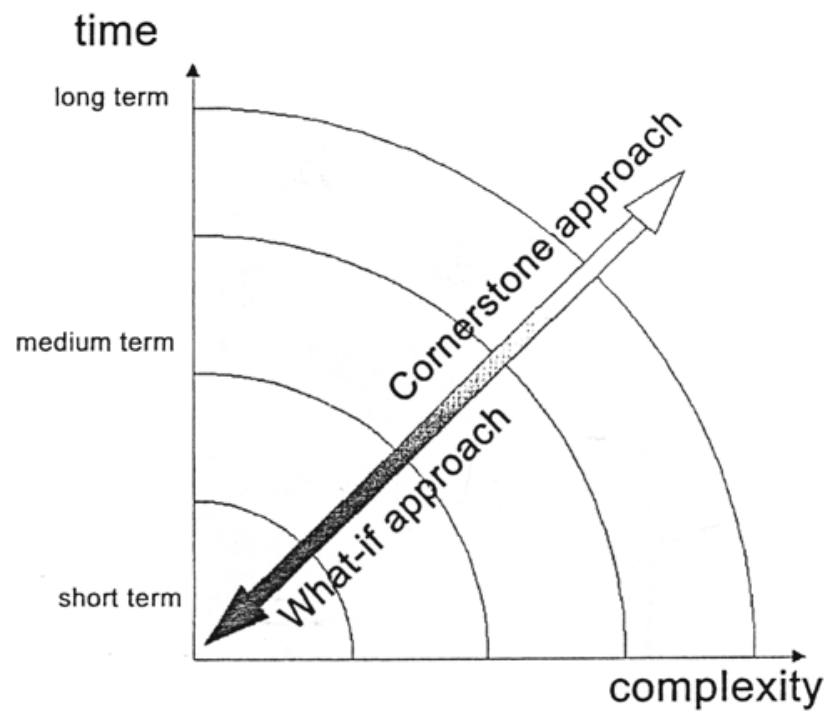

Fig. 2: Two basic approaches to scenario development in LCA research

Stevels (1997) has presented different levels in environmental improvement of products (see also Table 2):

- Level 1: Incremental improvement, which will result in improvements in the order of $5-10 \%$

- Level 2: Complete redesign of existing concepts, which will result in improvements of up to $30-50 \%$

- Level 3: Alternative fulfilment of functionality, which may result in improvements of up to $50-75 \%$

- Level 4: Change of functionality, which may result in more than $75 \%$ (factor 4 ) improvements

The levels of improvement suggested are a combination of technical, social, and institutional innovation. The higher levels of design require changes in society and require the engagement of multiple stakeholders. The time horizon of dif- ferent levels is also included in the table. The optimisation of existing systems concerns decisions with a short time horizon, while the change of product systems and improvements to existing technologies concern decisions over a medium time horizon. Fundamental changes of several technologies or concepts pertain to long term decisions. (see CHAINET, 1998).

The different levels of improvement also require different levels of information. Level 1 typically requires operational information and research in this case would use What-if scenarios. At level 4, instead, strategic information is required which makes the Cornerstone scenario approach more suitable for this case.

The second subgroup of the Working Group 'Scenario Development in LCA' will study the impact of scenarios on modelling and also discuss in detail how different scenarios should be incorporated into the modelling phase of LCA.

\section{Relation of Scenarios to the Conventional Phases of LCA}

The frames of scenarios are defined in the first phase of LCA, the goal and scope definition, but the details of these scenarios are worked out in the subsequent phases. As indicated in section 3, we distinguish between technology scenarios, environment scenarios, and valuation scenarios. These are connected to, respectively, the inventory analysis, the characterisation, and the weighting (SONNEMANN, 1999a). The details of technology scenarios are developed through the modelling in the inventory analysis. The details of environment and valuation scenarios are both developed in the impact assessment. Table 3 summarises the dimensions of LCA scenario frames that directly influence the modelling in the inventory analysis and impact assessment.

Table 3: Influence of LCA scenario development to inventory analysis and impact assessment

\begin{tabular}{lcc}
\hline $\begin{array}{c}\text { Dimension of } \\
\text { LCA scenario } \\
\text { development }\end{array}$ & $\begin{array}{c}\text { Direct influence } \\
\text { on inventory } \\
\text { analysis }\end{array}$ & $\begin{array}{c}\text { Direct influence } \\
\text { on impact } \\
\text { assessment }\end{array}$ \\
\hline System boundaries & $\mathrm{X}$ & \\
Allocation methods & $\mathrm{X}$ & \\
Technology & $\mathrm{X}$ & $\mathrm{X}$ \\
Time & $\mathrm{X}$ & $\mathrm{X}$ \\
Space & $\mathrm{X}$ & $\mathrm{X}$ \\
Characterisation & & $\mathrm{X}$ \\
methods & & \\
Weighting methods & & \\
\hline
\end{tabular}

Table 2: Levels of improvement (STEVELS, 1997)

\begin{tabular}{cccccc}
\hline $\begin{array}{c}\text { Level of } \\
\text { improvement }\end{array}$ & Goal & Example & $\begin{array}{c}\text { Time } \\
\text { horizon }\end{array}$ & $\begin{array}{c}\text { Change of consumer } \\
\text { lifestyle }\end{array}$ & $\begin{array}{c}\text { Infra- } \\
\text { structure change }\end{array}$ \\
\hline 1 & $\begin{array}{c}\text { Incremental } \\
\text { improvements } \\
2\end{array}$ & Current better TV & $0-2$ years & - & - \\
3 & $\begin{array}{c}\text { Redesign of existing } \\
\text { concepts }\end{array}$ & "Green TV" & $0-5$ years & + & - \\
& $\begin{array}{c}\text { Alternative fulfilment } \\
\text { of functionality } \\
4\end{array}$ & LCD TV & $0-10$ years & +++ & +++ \\
\hline
\end{tabular}




\subsection{Goal and scope definition}

Scenarios are a possible answer to specific questions in the goal definition and the scope of the study has to be defined accordingly. As stated above, the frames of the scenarios are defined in the goal and scope definition. The frames of a scenario include, but are not limited to, the aspects that are listed in Table 3, i.e. system boundaries, allocation methods, level of technology, temporal and geographical aspects, characterisation methods, and weighting methods.

The different scenarios are generally based on different sets of assumptions (BRAUNSCHWEIG \& JAHN, 1998). To facilitate an assessment of the validity of the different scenarios, these assumptions should be explicitly described in the goal and scope definition. As discussed in section 3.2, the assumptions behind the studied scenarios are often implicit. It would, however, be very important to state explicitly the underlying scenarios and the detailed assumptions connected to them in each LCA study.

\subsection{Inventory analysis}

The choice of data that are collected in the inventory analysis should be consistent with the scenario frames. Scenario development often leads to more complex data needs. If the study includes more than one scenario, data must be collected for each scenario. Furthermore, scenarios that are based on technology that is not yet in use will sometimes require that the input data be roughly guessed. Scenario development will therefore increase the need for methods how to treat uncertainties in the data as well as the need for a procedure for estimating input data.

The parts of the technological system (flows or processes) that dominate the results of the life cycle inventory analysis (LCI) can be identified through a dominance analysis. It is relevant to consider whether the different technology scenarios influence these parts. If this is not the case, the LCI results do not depend significantly on the choice of the scenario. There is no further need to investigate different technology scenarios, and the scenarios do not have to be regarded when conducting the uncertainty analysis. On the other hand, if the choice of the scenario has a large effect on the LCI results, the validity and probability of the scenarios should be discussed in the interpretation of the LCI results.

\subsection{Impact assessment}

Environmental scenarios and valuation scenarios are used in the life cycle impact assessment (LCIA). They correspond to two different elements of LCIA: characterisation and weighting (SONNEMANN, 1999a).

An environmental scenario is used for calculating the potential environmental effects of the emissions, etc. that are caused by the technological system. The frame of an environmental scenario can include, but is not restricted to geographical boundaries - e.g. global, European or national and temporal horizons. The environmental scenario also includes the model that is used for calculating the environmental effects.
Pollutants will often have environmental impacts long after they have been emitted. These long-term impacts depend on other events in the technological system and in the environment. Hence, the temporal horizons, at least, are affected by assumptions about future events. Comparing the concept of environmental scenarios to the scenario definition earlier in this article, it can be concluded that the temporal horizon adds the essential future perspective and that the environmental scenario is based on assumptions about future events and the path from the present to this future. The geographical area in which the model is applied is a necessary part of the description to specify the scenario (SONNEMANN, 1999a).

Weighting factors can be obtained by various approaches. The choice of one specific method can be considered as a choice of one specific valuation scenario. Moreover, the weighting factor itself can depend on scenarios about future damages (SONNEMANN, 1999a).

\subsection{Interpretation}

The objective of the interpretation is to determine the significant issues, in accordance to the goal and scope definition. The scenarios have to be checked for completeness, sensitivity, and consistency (see ISO 14043, 1998). Moreover, the uncertainty of the results has to be analysed and the quality of data assessed. The procedure is iterative and interactive with other phases of LCA. Finally, in the conclusions also the strengths and limits of the scenarios have to be considered and reported if the choice of scenario is important for the LCA results (SONNEMANN, 1999b).

When presenting the results of a multiple scenario study, the issue of uncertainties included in each of the scenarios becomes extremely important. The decision-maker has to be fully aware of the uncertainties underlying each scenario in order to be able to make comparisons between them. Uncertainty in scenario development will be discussed briefly in the next section.

\section{Uncertainty in Scenario Development}

If the outcome of a future event is sure, we speak of certainty. In this case the probability of the future event is either 1 or 0 . Correspondingly, a future event is uncertain if the probability of the event is neither 1 nor 0 . It is, however, not enough to know that a situation is uncertain, but we should also know how uncertain it is (GAUSEMEIER et al., 1995).

Uncertainty is no occasional, temporary phenomenon from a reasonable predictability but, instead, it is a basic structural feature of the environment. Scenarios acknowledge uncertainty and aim at structuring and understanding it - but not by merely criss-crossing variables and producing dozens or hundreds of outcomes. Instead, they create a few alternative and internally consistent pathways into the future (WACK, 1985b). Scenarios must help decision-makers develop their own feel for the nature of the system, the forces at work within it, the uncertainties that underlie the alternative scenarios, and the concepts useful for interpreting key data (WACK, 1985b). When presenting the results of a multiple scenario study, the issue of uncertainties included in each of the scenarios becomes ex- 
tremely important. The decision-maker has to be fully aware of the uncertainties in each scenario in order to be able to make comparisons berween them.

Uncertainty in LCAs arises because of several different reasons. Huijbregts (1998) distinguishes between 6 sources of uncertainty and variability in LCA: parameter uncertainty, model uncertainty, uncertainty due to choices, spatial variability, temporal variability, and variability between sources and objects (HuijBregts, 1998). Most of these uncertainties are a problem in every LCA. The probability of a certain future development is dependent on the probabilities of those factors, which have been chosen to describe/reflect/model the selected scenario.

In prospective studies the parameter uncertainty will most probably be of great importance as well as the model uncertainties. Uncertainties due to spatial variability, instead, bring nothing new for prospective studies compared to any study. Uncertainties due to temporal variability neither. Maybe the time range is larger, but the problems are the same as in any study. Variability between objects/sources is an issue, which refers to the choice of input data, i.e. sitespecific, average, or marginal data. This issue is discussed in detail within the second subgroup (the LCI modelling task) of the Working Group.

Huijbregts (1998) has offered some solutions on how to deal with the above-discussed issues of uncertainty within LCAs. The tools available to address different types of uncertainty and variability in LCAs include probabilistic simulation, correlation and regression analysis, additional measurements, scenario modelling, standardisation, expert judgement or peer review, non-linear modelling, and multi-media modelling. According to Huijbregt (1998), scenario modelling should be useful especially in cases where there is uncertainty about choices and temporal variability.

\section{Conclusions}

Scenarios are in one way or another an integral part of any LCA. However, they are not always dealt with explicitly and there has so far been no general LCA framework or procedure available on the systematic development of scenarios. To deal with these issues, the Working Group 'Scenario Development' in LCA of SETAC-Europe was founded. In the first phase the Working Group has examined how and for what reasons different scenarios are developed for an LCA study. As a conclusion of the first phase, the group suggests two basic approaches for scenario development in LCA studies: Cornerstone and What-if scenarios presented in this article. The next phases will concentrate on the modelling issues of scenarios and a review on case studies that have used scenarios and also reported them explicitly or implicitly. The final results of the Working Group should result in a framework or guideline possibly enhancing or expanding the standardisation documents of the ISO 14040 series.

\section{References}

BARTUSiK, K.; CABALA, P. (1997): Metoda scenariuszy w planowaniu strategicznym. Przeglad Organizacji No. 2, 20-25
Braunschweig, A.; JAHN, C. (1998): Relation of scenario development to the conventional phases of LCA. Working paper for SETAC working group Scenario development, unpubl.

BuRns, A.C.; Bush, R.F. (1998): Marketing Research. Prentice Hall, Upper Saddle River, NJ, USA

CASPERSEN, N.; WeIDENAA, B.P. (unpubl.): Future forecasting methods for life cycle assessments, Unpublished manuscript

CHAINET (1998): Definition Document. Leiden, The Netherlands

COATES, J.F. (1994): Normative forecasting. United Nations University, Washington D.C., USA.

Futures Group (1994a): Statistical modelling From time series to simulation. United Nations University, Washington D.C., USA

Futures Group (1994b): Relevance tree and morphological analysis. United Nations University, Washington D.C., USA

Futures Group (1994c): Scenarios. United Nations University, Washington D.C., USA

Gausemeier, J.; Fink, A.; Schlake, O. (1995): Szenario-Management, Planen und Führen mit Szenarien. Carl Hanser Verlag, München, Germany

GlenN, J.C. (1994a): The futures wheel. United Nations University, Washington D.C., USA

GlenN, J.C. (1994b): Participatory methods. United Nations University, Washington D.C., USA

GLENN, J.C. (1994c): Introduction to the futures research methodology series. United Nations University, Washington D.C., USA

Gordon, T.J. (1994): The Delphi method. United Nations University, Washington D.C., USA

Gordon, T.J.; GlENN, J.C. (1994): Environmental scanning. United Nations University, Washington D.C., USA

Hansmann, K.W. (1983): Kurzlehrbuch Prognosenverfahren. Mit Aufgaben und Lösungen. Wiesbaden, Germany

HoKKANEN, J. (1997): Aiding public environmental decision making by multicriteria analysis. University of Jyväskylä, Department of Mathematics, Report 72, Jyväskylä, Finland

HujbREGTS, M.A. (1998): Application of Uncertainty and Variability in LCA. International Journal of LCA 3, 273-280

Hunt, D.; Johnson, C. (1995): Environmental Management Systems. McGraw-Hill Book Company, London, UK

ISO/DIS 14040 (1997): Environmental management - Life cycle assessment - Principles and framework

ISO/DIS 14043 (1998): Environmental management - Life cycle assessment - Life Cycle Interpretation. Draft International Standard

Linneman, R.; Klein, H. (1982): The Use of Multiple Scenarios by U.S. Industrial Companies. Temple University, USA

MALASKA, P. (1983): Coping with unpredictability and uncertainty of the future. Publications of the Turku School of Economics, Series A1:1983, Turku, Finland

MaLASKA, P. (1984): Multiple scenario approach and strategic behaviour in European companies. Publications of the Turku School of Economics, Discussion and working papers 1:1984, Turku, Finland

MannermaA, M. (1999): Tulevaisuuden hallinta - skenaariot strategiatyöskentelyssä. WSOY, Turku, Finland

Meadows, D.H.; Meadows, D.C.; Randers, J.; BeHrens, W.W. (1972): Limits to growth. Universe Books, New York, USA

MERISTO, T. (1991): Skenaariotyöskentely yrityksen johtamisessa. VAPK-Kustannus, Helsinki, Finland

PEsonen, H-L. (1998): Scenarios in LCA research. Working paper 190/1998, University of Jyväskylä, School of Business and Economics, Jyväskylä, Finland

vON REIBNITZ, U. (1991): Szenario-Technik, Instrumente für die unternehmerische und persönliche Erfolgsplanung. Gabler, Wiesbaden, Germany 
Scholz, R.W.; TIETJE, O. (1996): Methoden der Fallstudie, in Industrieareal Sulzer-Escher Wyss. vdf Hochschulverlag, Zürich, Switzerland

SONNEMANN, G. (1999a): Scenarios and modelling in the characterisation and weighting within LCIA (First ideas on environmental modelling). Working paper for SETAC working group Scenario development, unpubl.

Sonnemann, G. (1999b): Scenarios and modelling in the interpretation within LCIA. Working paper for SETAC working group Scenario development, unpubl.

STEVELS, A. (1997): Moving companies towards sustainability through eco-design: Conditions for success. Journal of Sustainable Product Design

The Futures Group (1994): Scenarios. United Nations University, Washington D.C., USA

VANSTON, J.H. (1995): Technological forecasting: An aid to Effective Technology Management. Technology Futures Inc, Austin, USA

VARTIA, P. (1994): Talouden ennustamisen vaikeus. The Research Institure of the Finnish Economy, Helsinki, Finland

WACK, P. (1985a): Scenarios: uncharted waters ahead. Harvard Business Review 63 No. 5, 73-89
WACK, P. (1985b): Scenarios: shooting the rapids. Harvard Business Review 63 No. 6, 139-150

WEIDEMA, B.P. (1993): Development of a methodology for product life cycle assessment with special emphasis on food products. Summary of Ph.D. thesis, Interdisciplinary Centre, Technical University of Denmark, Lyngby, Denmark

WEIDEMA, B.P. (1998a): Application typologies for life cycle assessment - A review. International Journal of LCA 3, 237-240

WEIDEMA, B.P. (1998b): New developments in the methodology for life cycle assessment. Handout for presentation at the $3^{\text {rd }}$ International Conference on Ecobalance, Tsukuba 1998.11.25-27. http://www.ipt.dtu.dk/employ/bow/Developh.htm

Welford, R. (1994): Cases in Environmental Management and Business Strategy. Pirman Publishing. London, UK

World Business Council for Sustainable Development (WBCSD) (1997): Exploring Sustainable Development. WBCSD Global Scenarios 2000-2050 Summary Brochure.

Received: November 3rd, 1999 Accepted: December 16th, 1999 Online Publication: December 21st, 1999

Special Issue: LCA in Japan

Publication: September 2000 (Int. J. LCA No. 5, 2000)

\section{Editors}

Dr. Matthias Finkbeiner, DaimlerChrysler AG, Stuttgart, Germany

Dr. Yasunari Matsuno, National Institute for Resources and Environment, AIST, MITI, Tsukuba, Japan

\section{Overall Topics}

Representative coverage of both methodology (inventory assessment, impact assessment, etc.) and application (case studies) of LCA in Japan from a broad spectrum of authors (industry, research institutes, universities); activities of JLCA (Japan Life Cycle Assessment Society) and JEMAI (Japan Environmental Management Association for Industry).

Japanese authors interested in submitting a paper are asked to contact the Issue Editors immediately.

For further information, please contact

Dr. Matthias Finkbeiner, DaimlerChrysler, Stuttgart, Germany

e-mail: matthias.finkbeiner@daimlerchrysler.com

\begin{tabular}{|c|c|c|c|}
\hline Authors & Occupation & Section/Division & Subject \\
\hline Yukiyoshi HATORI & EBARA Corp. & $\begin{array}{l}\text { Environmental Engineering } \\
\text { Group }\end{array}$ & $\begin{array}{l}\text { LCA for Treatment System of Organic Waste } \\
\text { Mainly from Municipal Waste and Agricultural Field }\end{array}$ \\
\hline Kentaro HAYASHI & $\begin{array}{l}\text { Pacific Consultants, } \\
\text { Co., Ltd }\end{array}$ & Environmental Dept. & Damage Function of Ozone Depletion for LCIA \\
\hline Atsusi INABA & NIRE & Energy Resources Dept. & Recent Progress of LCA Activities in Japan \\
\hline Norihiro ITSUBO & JEMAI & Technial Planning & Screening Impact Assessment Based on Simplified Damage Functions \\
\hline $\begin{array}{l}\text { Ryuji MATSUHASHI, } \\
\text { et al. }\end{array}$ & $\begin{array}{l}\text { The University of } \\
\text { Tokyo }\end{array}$ & $\begin{array}{l}\text { Dept. of Geosystem Engineering, } \\
\text { Faculty of Engineering }\end{array}$ & $\begin{array}{l}\text { Life Cycle } \mathrm{CO}_{2} \text {-Emissions of Electric Vehicles and Gasoline Vehicles } \\
\text { Utilizing a Process-Relational Model }\end{array}$ \\
\hline Yasunari MATSUNO & NIRE & Energy Resources Dept. & $\begin{array}{l}\text { Development of Life Cycle Inventories for } \\
\text { Electricity Grid Mixes in Japan }\end{array}$ \\
\hline Yuichi MORIGUCHI & NIES & & \\
\hline Kazuta YANAGITANI & DAIKIN & MEL & LCA Study of Air Conditioners with an Alternative Refrigerant \\
\hline Masataka YANO & JEMAI & Technical Planning & National LCA Project in Japan \\
\hline
\end{tabular}

